\title{
ТАКТИКА В ДІАГНОСТИЦІ ТА ЛІКУВАННІ ХВОРИХ З ПОЄДНАНОЮ НЕЙРОГЕННОЮ ПАТОЛОГІЕЮ НИЖНІХ СЕЧОВИХ ШЛЯХІВ ТА ДИСТАЛЬНОГО ВІДДІЛУ ТОВСТОЇ КИШКИ
}

\author{
๑С. О. Возіанов, М. П. Захараш, П. В. Чабанов, Ю. М. Захараш, \\ Н. А. Севастьянова, В. Ю. Угаров, А. С. Репринцева \\ ДУ «Інститут урології НАМН України» м. Київ \\ Національний медичний університет імені О. О. Богомольчя, м. Київ \\ КНП «ЦПМСД № 2» Солом'янського району, м. Київ
}

РЕЗЮМЕ. Вступ. Нейрогенні розлади сечовипускання об' єднують велику групу порушень, що виникають при ураженні головного і спинного мозку, провідних шляхів і центрів сечового міхура. Це вказує на актуальність проблеми та необхідність розробки методів діагностики і одночасного їх лікування.

Мета дослідження - підвищення ефективності лікування хворих з поєднаною нейрогенною патологією нижніх сечових шляхів та дистального відділу товстої кишки.

Матеріал і методи. Всі хворі на поєднану нейрогенну патологію нижніх відділів сечовивідної системи і нижніх відділів товстої кишки проходили комплексне обстеження з використанням як загальноприйнятих, так і спеціальних методів діагностики.

Для дослідження функціонального стану м'язів, які забезпечують динамічну активність нижніх сечових шляхів та дистальних відділів товстої кишки, ми використовували електроміографію (ЕМГ) сечового міхура i сфінктерного апарату, анального сфінктера, м' язів тазового дна. Для підсилення біоелектричної активності м' язів нижніх відділів сечової системи та дистальних відділів товстої кишки використовували електроміограф 4-канальний фірми «Медікор» (Угорщина). Дані ЕМГ оцінювали за показниками середнього значення сумарної біоелектричної активності.

Результати. У статті представлені результати лікування хворих з поєднаною нейрогенною патологією нижніх сечових шляхів і дистального відділу товстої кишки. Оцінку ефективності проводили за допомогою клінічних та уродинамічних обстежень. Встановлено, що електроміографія та урофлоуметрія відображають функціональний стан сечовивідних шляхів і дистальних відділів товстої кишки при їх поєднаній патології. Отримані результати були основою для обґрунтування принципів диференційного лікування хворих з поєднаною нейрогенною патологією нижніх сечовивіднихшляхів і дистальних відділів товстої кишки, що дозволило підвищити ефективність лікування. Консервативне лікування пацієнтів даної категорії за допомогою електростимуляції $\epsilon$ ефективним.

Висновки. 1. Дані електроміографічних та уродинамічних досліджень дозволили розробити та оптимізувати методи лікування залежно від стану тонусу нервово-м'язових структур нижніх сечових шляхів та дистальних відділів товстої кишки. 2. Комплексний диференційний підхід до консервативного лікування спрямований на корекцію виявлених при електрофізіологічному та уродинамічному обстеженнях порушень функціонального стану нижніх сечовивідних шляхів і дистальних відділів товстої кишки.

КЛЮчОВІ СЛОВА: нейрогенні розлади сечовипускання; нейрогенна дисфункція кишечника; урофлоуметрія; електроміографія; електростимуляція.

Вступ. Нейрогенні розлади сечовипускання о6'єднують велику групу порушень сечовипускання, які виникають при ураженні головного і спинного мозку, провідних шляхів і центрів сечового міхура. Однак у рішенні цього питання не приділялося достатньої уваги розладам функції товстої кишки, що часто супроводжують розлади акту сечовипускання. Несприятливий вплив запорів на функцію не тільки сечового міхура, а й верхніх сечових шляхів, описано у літературі $[1,2]$.

3 цих позицій доцільно говорити про нейрогенні розлади функції тазових органів. До теперішнього часу поєднаним дисфункціям не надавалося належної уваги ні в теоретичному, ні в практичному аспектах. Все це вказує на актуальність проблеми та необхідність розробки методів діагностики і одночасного їх лікування [3-7].

Мета дослідження - підвищення ефективності лікування хворих з поєднаною нейроген- ною патологією нижніх сечових шляхів та дистального відділу товстої кишки.

Матеріал і методи дослідження. Всі хворі на поєднану нейрогенну патологію нижніх відділів сечовивідної системи і нижніх відділів товстої кишки проходили комплексне обстеження з використанням як загальноприйнятих, так і спеціальних методів діагностики.

Для дослідження функціонального стану м'язів, які забезпечують динамічну активність нижніх сечових шляхів та дистальних відділів товстої кишки, ми використовували електроміографію (ЕМГ) сечового міхура і сфінктерного апарату, анального сфінктера, м'язів тазового дна. Для підсилення біоелектричної активності м'язів нижніх відділів сечової системи та дистальних відділів товстої кишки використовували електроміограф 4-канальний фірми «Медікор» (Угорщина). Дані ЕМГ оцінювали за показниками серед- 
Огляди літератури, оригінальні дослідження, погляд на проблему

нього значення сумарної біоелектричної активHOCTi.

Хворий при проведенні електроміографії перебував у гінекологічному кріслі, вводили стерильний електрод-катетер у сечовий міхур, потім інший електрод-катетер вводили в пряму кишку, відведення біопотенціалів детрузора та прямої кишки проводили при безпосередньому контакті електрода із стінкою спорожненого сечового міхура та спорожненого дистального відділу товстої кишки, визначення рівня розташування сприймаючої частини електрода в нижніх сечових шляхах та дистальних відділах товстої кишки здійснювали відповідно до характеру біоелектричної активності сигналів на екрані, а саме за існуючими відмінностями між високочастотною низькоамплітудною біоелектричною активністю поперечносмугастих м'язів (рівень сфінктера уретри та рівень сфінктера товстої кишки) і низькочастотною високоамплітудною біоелектричною активністю гладких м'язів детрузора та стінки товстої кишки, кількісну оцінку функції м' язів, за даними електроміографії, здійснювали відповідно до показників середнього значення сумарної біоелектричної активності та частоти проходження імпульсів.

Урофлоуметрію проводили за допомогою апарата MERCUR 4000. На цьому обладнанні дані одразу оброблялись та видавались у вигляді графіка з відповідними цифровими характеристиками. Метод дає інформацію про загальну функцію нижніх сечовивідних шляхів з виведення сечі.

Для проведення електростимуляції хворого укладали на спину, процедуру проводили при спорожненому сечовому міхурі та дистальному відділі товстої кишки електростимулятором із застосуванням двох пластинчастих електродів, змочених фізіологічним розчином, які розташовують на спині на рівні хребців S2-S4 перпендикулярно до хребта, інший - у нижній ділянці живота над лоном.

Результати й обговорення. В групу дослідження увійшли 27 чоловіків, середній вік яких склав $(38,1 \pm 1,8)$ років, тривалість захворювання у них становила $(18,4 \pm 1,6)$ місяців.

У хворих цієї групи середній показник полакіурії до лікування склав $(3,1 \pm 0,6)$ раза, ніктурії $(2,1 \pm 0,5)$ раза на добу, імперативні поклики склали $(3,2 \pm 0,7)$ раза на добу, а імперативне нетримання сечі спостерігали $(2,5 \pm 0,5)$ раза на добу. Оцінка за опитувальником РРВС склала $(4,2 \pm 0,3)$ бали.

При оцінюванні симптомів клінічних проявів патології дистальних відділів товстої кишки у чоловіків до лікування ми спостерігали наступне: запор відмічався у хворих $(4,7 \pm 0,8)$ раза, нетримання газів - $(4,2 \pm 0,8)$ раза, нетримання рідкого калу - $(2,4 \pm 0,4)$ раза, нетримання твердого калу -
$(1,4 \pm 0,3)$ раза. При оцінюванні за опитувальником CRADI-8 у цієї групи хворих до лікування ми отримали $(18,9 \pm 1,2)$ балів.

При проведенні ЕМГ м' язових структур сечового міхура та товстої кишки ми отримали середнє значення різниці біопотенціалів: детрузора - $(25,9 \pm$ $1,1)$ мкВ, стінки товстої кишки - $(46,3 \pm 1,3)$ мкВ, на внутрішньому сфінктері сечового міхура - $(22,5 \pm$ $1,0)$ мкВ, на зовнішньому сфінктері- $(38,6 \pm 1,2)$ мкВ. При оцінюванні сфінктерного апарату товстої кишки ми спостерігали на внутрішньому сфінктеpi $(40,5 \pm 1,6)$ мкB, а на зовнішньому сфінктері $(51,6 \pm 1,8)$ мкВ.

При проведенні урофлоуметрії у хворих цієї групи ми отримали наступне середнє значення основних показників: об'єм сечовипускання (V) склав

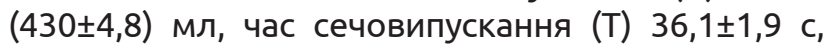
максимальна об'ємна швидкість потоку сечі (Qmax) $(14,9 \pm 1,2)$ мл/с, середня швидкість сечовипускання (Qave) $(12,6 \pm 1,2)$ мл/с, час досягнення максимальної швидкості (TQ max) - $(11,2 \pm 0,8)$ с.

Ефективність лікування ми оцінювали після першого, третього та шостого курсів терапії, в результаті отримали наступні дані.

Показник полакіурії після першого курсу лікування склав $(4,2 \pm 0,6)$ раза ( $>>0,2)$, тобто зменшився на $26,1 \%$, показник ніктурії - $(1,6 \pm 0,5)$ раза на добу (р>0,2), що відповідає зменшенню на 31,3 \%, імперативні позиви склали $(2,9 \pm 0,6)$ раза на добу ( $p>0,2)$, що відповідає зменшенню на 10,3 \%, а імперативне нетримання сечі відмічалось $(1,9 \pm$ $0,8)$ рази на добу $(p>0,2)$, тобто зменшилося на 31,6 \%. При оцінці результатів за опитувальником PPBC ми виявили покращення на $7,7 \%$, а саме $(3,9 \pm 0,8)$ бала $(p>0,2)$.

При оцінці симптомів дистальних відділів товстої кишки у хворих цієї групи ми зафіксували наступні зміни: кількість запорів зменшилась у хворих $(4,1 \pm 1,1)$ раза, $14,6 \%$, (р>0,2), нетримання газів - до $(3,4 \pm 1,2)$ раза, $23,5 \%$, $(p>0,2)$, нетримання рідкого калу у пацієнтів цієї групи $(1,9 \pm 0,2)$ раза, $26,3 \%$, (p>0,2), нетримання твердого калу у чоловіків $(1,1 \pm 0,1)$ раза, $27,3 \%$, $(p>0,2)$. При оцінці результатів за опитувальником CRADI-8 ми отримали зменшення до $(16,5 \pm 1,2)$ бала, $14,5 \%,(p>0,2)$.

Після першого курсу лікування ЕМГ м'язових структур сечового міхура та товстої кишки ми отримали наступне середнє значення різниці біопотенціалів: детрузора - $(26,4 \pm 1,0)$ мкВ, де покращення склало 1,9\%, (p>0,2), стінки товстої кишки $(48,2 \pm 1,2)$ мкB, 3,9\%, (p>0,2), на внутрішньому сфінктері сечового міхура $(24,1 \pm 1,3)$ мкB, 6,6 \%, ( $>>0,2)$, на зовнішньому сфінктері $(39,6 \pm 1,4)$ мкB, 2,5\%, (р>0,2). При оцінці сфінктерного апарату товстої кишки ми спостерігали на внутрішньому 
Огляди літератури, оригінальні дослідження, погляд на проблему

сфінктері $(42,3 \pm 1,2)$ мкВ, 4,3\%, (p>0,2), на зовнішньому сфінктері - $(53,2 \pm 1,5)$ мкВ, $3 \%$, $(p>0,2)$ відповідно.

Стосовно динаміки змін показників УФМ ми отримали наступне: об'єм сечовипускання (V) склав $(425 \pm 3,5)$ мл, 1,2 \%, (p>0,2), час сечовипускання (T) - $(34,8 \pm 2,9)$ c, 3,7\%, ( $>0,2)$, максимальна об'ємна швидкість потоку сечі (Qmax) $(16,3 \pm 1,3)$ мл/с, 8,6 \%, (р>0,2), середня швидкість сечовипускання (Qave) - $(13,5 \pm 0,8)$ мл/c, 6,7 \%, $(p>0,2)$, час досягнення максимальної швидкості (TQ $\max )(10,5 \pm 1,1) c, 6,7 \%,(p>0,2)-(1,6 \pm 0,5)$ раза, $56,3 \%(p>0,2)$.

Оцінюючи ефективність лікування після третього курсу за допомогою опитувальника РРВС отримано $(3,1 \pm 0,9)$ бала, 35,5 \% (р<0,001).

Аналізуючи динаміку змін симптомів дистальних відділів товстої кишки у хворих цієї групи ми зафіксували, що кількість запорів у хворих зменшилась $(3,9 \pm 0,9)$ раза, 20,5\%, (p>0,2), нетримання газів - $(2,9 \pm 1,1)$ раза, 44,8 \% (р>0,2), нетримання рідкого калу у пацієнтів цієї групи - $(1,7 \pm 0,1)$ раза, $41,2 \%$, ( $<<0,1)$, нетримання твердого калу у чоловіків - $(0,9 \pm 0,1)$ раза, 55,6 \%, $(p<0,2)$. При оцінюванні за опитувальником CRADI-8 ми отримали зменшення до $(12,5 \pm 1,2)$ бала, $51,2 \%$ ( $p<0,05)$.

За результатами третього курсу лікування ми отримали наступні показники різниці біопотенціалів м'язових структур сечового міхура та товстої кишки: детрузора $(31,9 \pm 1,5)$ мкВ, покращення склало 18,8 \%, (p<0,01), стінки товстої кишки $(56,3 \pm 1,6)$ мкB, $17,8 \%$, ( $<<0,001)$, на внутрішньому сфінктері сечового міхура $(27,2 \pm 1,5)$ мкB, $17,3 \%$, $(p<0,05)$, на зовнішньому сфінктері $(42,4 \pm 1,3)$ мкB, $9 \%,(p<0,05)$. При оцінюванні сфінктерного апарату товстої кишки ми спостерігали на внутрішньому сфінктері $(54,5 \pm 1,0)$ мкB, 25,7 \% $(p<0,05)$, на зовнішньому сфінктері - $(76,3 \pm 1,9)$ мкВ, 32,4 \%, ( $p<0,001)$ відповідно.

Показники УФМ після 3 курсу лікування наступні: об'єм сечовипускання (V) склав $(340 \pm 2,3)$ мл, 26,5 \%, (p<0,05), час сечовипускання (T) - $(21,5 \pm 1,5)$ c, 68 \%, (p<0,05), максимальна об'ємна швидкість потоку сечі (Qmax) $(21,7 \pm 1,3)$ мл/с, 9,7\%, (p<0,05), середня швидкість сечовипускання (Qave) $(15,3 \pm 0,9)$ мл/с, 17,7 \%, $(p<0,2)$, час досягнення максимальної швидкості (TQ max) - $(9,9 \pm 1,4) c, 13,1 \%,(p>0,2)$.

Після завершення 6 курсів лікування у хворих цієї групи відмічалось значне покращення як клінічних, так і показників ЕМГ та УФМ. Ми зафіксу- вали, що полакіурія склала до $(8,2 \pm 0,9)$ раза на день, 62,2 \%, ( $p<0,001)$, ніктурії $(1,1 \pm 0,05)$ раза, 90,9 \%, (р<0,05), імперативні позиви зменшились до $(1,7 \pm 0,2)$ раза на добу, 88,2 \%, ( $<<0,05)$, нетримання сечі - $(1,4 \pm 0,1)$ раза, 78,6 \%, $(p<0,05)$.

Оцінка ефективності лікування, встановлена за опитувальником РPBC, виявила покращення, яке склало $(2,3 \pm 0,1)$ бала, 82, \%, $(p<0,001)$.

Симптоми дистальних відділів товстої кишки у хворих цієї групи змінилися наступним чином: кількість запорів зменшилась до $(2,5 \pm 0,8)$ раза, $88 \%,(p<0,05)$, нетримання газів - до $(2,3 \pm 05)$ раза, $82,6 \%$, ( $<0,05)$, нетримання рідкого калу у пацієнтів цієї групи до $(1,3 \pm 0,1)$ раза, 84, \%, (p<0,01), нетримання твердого калу - $(0,8 \pm 0,02)$ разів, $75 \%$, $(p<0,05)$. При оцінюванні за опитувальником CRADI-8 ми отримали зменшення до $(10,6 \pm 1,1)$ балів, 78,3\%, ( $p<0,05)$.

Різниця біопотенціалів м'язових структур сечового міхура та товстої кишки була наступною: детрузора - $(34,1 \pm 1,2)$ мкВ, де покращення склало $24 \%$, (р<0,001), стінки товстої кишки $(58,5 \pm 1,4)$ мкB, 20,9 \%, ( $<<0,001)$, на внутрішньому сфінктері сечового міхура - $(29,9 \pm 1,2)$ мкВ, 24,7 \%, ( $<<0,001)$, на зовнішньому сфінктері $(45,3 \pm 1,3)$ мкB, 14,8 \%, ( $p<0,001)$. При оцінюванні сфінктерного апарату товстої кишки ми спостерігали на внутрішньому сфінктері $(56,8 \pm 1,9)$ мкВ, $28,7 \%$, ( $p<0,001)$, на зовнішньому сфінктері $(79,9 \pm 2,0)$ мкВ, 35,4 \%, ( $<<0,001)$ відповідно.

Показники УФМ після 6 курсу лікування наступні: об'єм сечовипускання (V) склав $(310 \pm 4,5)$ мл, $38,8 \%$, (p<0,02), час сечовипускання (T) $(18,5 \pm 1,3)$ c, 95,1\%, (p<0,01), максимальна об 'ємна швидкість потоку сечі (Qmax) $(25,4 \pm 1,2)$ мл/с, $22,9 \%$, ( $<<0,001)$, середня швидкість сечовипускання (Qave) $(17,5 \pm 1,3)$ мл/с, $28 \%$, ( $<<0,01)$, час досягнення максимальної швидкості (TQ max) $(7,3 \pm 0,9)$ с, 53,4 \%, ( $p<0,01)$

Висновки. 1. Дані електроміографічних та уродинамічних досліджень дозволили розробити та оптимізувати методи лікування залежно від стану тонусу нервово-м'язових структур нижніх сечових шляхів та дистальних відділів товстої кишки.

2. Комплексний диференційний підхід до консервативного лікування спрямований на корекцію виявлених при електрофізіологічному та уродинамічному обстеженнях порушень функціонального стану нижніх сечовивідних шляхів і дистальних відділів товстої кишки. 
Огляди літератури, оригінальні дослідження, погляд на проблему ЛІТЕРАТУРА

1. Drake M. J. Neural control of the lower urinary and gastrointestinal tracts: supraspinal CNS mechanisms / M. J. Drake, C. J. Fowler, D. Griffiths // Neurourology and Urodynamics. - 2010. - Vol. 29, No. 1. - P. 119-127.

2. Samaranayake C. B. Systematic review on ventral rectopexy for rectal prolapse and intussusception / C. B. Samaranayake, C. Luo, A. W. Plank // Colorectal disease: the Official Journal of the Association of Coloproctology of Great Britain and Ireland. - 2010. - Vol. 12 (6). P. 504-512.

3. Bladder and bowel symptoms among adults presenting with low back pain to an Academic Chiropractic Clinic: Results of a preliminary study / A. L. Walden, S. A. Salsbury, W. R. Reed, D. J. Lawrence // Journal of Chiropractic Medicine. - 2014. - Vol. 13, No. 3. - P. 178-187.

4. Nygaard I. Exploring the association between life-

\title{
REFERENCES
}

1. Drake, M.J., Fowler, C.J., \& Griffiths, D. (2010). Neural control of the lower urinary and gastrointestinal tracts: Supraspinal CNS mechanisms. Neurourology and Urodynamics, 29, 1, 119-127.

2. Samaranayake, C.B., Luo, C., Plank, A.W., Merrie, A.E., Plank, L.D., \& Bissett, I.P. (2010). Systematic review on ventral rectopexy for rectal prolapse and intussusception. Colorectal disease: the Official Journal of the Association of Coloproctology of Great Britain and Ireland, 12 (6), 504-512.

3. Walden, A.L., Salsbury, S.A., Reed, W.R., \& Lawrence, D.J. (2014). Bladder and bowel symptoms among adults presenting with low back pain to an Academic Chiropractic Clinic: Results of a preliminary study. Journal of Chiropractic Medicine, 13 (3), 178-187.

4. Nygaard, I., Shaw, J., \& Egger, M.J. (2012). Exploring the association between lifetime physical activity and pel-

time physical activity and pelvic floor disorders: study and design challenges / I. Nygaard, J. Shaw, M. J. Egger // Contemp. Clin. Trials. - 2012. - Vol. 33 (4). - P. 819-827.

5 . Urinary incontinence in degenerative spinal disease / R. J. De, M. Benco, B. Kolarovszki [et al.] // Acta Chir. Orthop. Traumatol. Cech. - 2011. - Vol. 78. - P. 67-70.

6. Abrams P. Fourth International Consultation on Incontinence Recommendations of the International Scientific Committee: Evaluation and treatment of urinary incontinence, pelvic organ prolapse and fecal incontinence / P. Abrams, K. E. Andersson, L. Birder // Neurourol. Urodyn.2010. - Vol. 29. - P. 213-240.

7. Glasgow S. C. Preoperative anal manometry predicts continence after perineal proctectomy for rectal prolapse / S. C. Glasgow, E. H. Birnbaum, I. J. Kodner // Dis. Colon Rectum. - 2006. - Vol. 49 (7). - P. 1052-1058.

vic floor disorders: study and design challenges. Contemp. Clin. Trials., 33 (4), 819-827.

5. De, R.J., Benco, M., Kolarovszki, B., Luptak, J., \& Svihra, J. (2011). Urinary incontinence in degenerative spinal disease. Acta Chir. Orthop. Traumatol. Cech., 78, 67-70.

6. Abrams, P., Andersson, K.E., \& Birder, L. (2010). Fourth International Consultation on Incontinence Recommendations of the International Scientific Committee: Evaluation and treatment of urinary incontinence, pelvic organ prolapse and fecal incontinence. Neurourol. Urodyn., 29, 213-240.

7. Glasgow, S.C., Birnbaum, E.H., Kodner, I.J., Fleshman, J.W., \& Dietz, D.W. (2006). Preoperative anal manometry predicts continence after perineal proctectomy for rectal prolapse. Dis. Colon Rectum, 49 (7), 1052-1058.

\section{ТАКТИКА ДИАГНОСТИКИ И ЛЕЧЕНИЯ БОЛЬНЫХ С СОЧЕТАННОЙ НЕЙРОГЕННОЙ ПАТОЛОГИЕЙ НИЖНИХ МОЧЕВЫХ ПУТЕЙ И ДИСТАЛЬНОГО ОТДЕЛА ТОЛСТОЙ КИШКИ}

\author{
๑С. О. Возианов, М. П. Захараш, П. В. Чабанов, Ю. М. Захараш, \\ Н. А. Севастьянова, В. Ю. Угаров, А. С. Репринцева \\ ГЗ «Институт урологии НАМН Украины», г. Киев \\ Национальный медицинский университет имени А. А. Богомольца, г. Киев \\ КНП «ЦПМСД № 2» Соломенского района, г. Киев
}

РЕЗЮМЕ. Введение. Нейрогенные расстройства мочеиспускания объединяют большую группу нарушений мочеиспускания, возникающих при поражении головного и спинного мозга, проводящих путей и центров мочевого пузыря. Это указывает на актуальность проблемы и необходимость разработки методов диагностики и одновременного их лечения.

Цель исследования - повышение эффективности лечения больных с сочетанной нейрогенной патологией нижних мочевых путей и дистального отдела толстой кишки.

Материалы и методы. Все больные с совмещенной нейрогенной патологией нижних отделов мочевыводящей системы и нижних отделов толстой кишки проходили комплексное обследование с использованием как общепринятых, так и специальных методов диагностики.

Для исследования функционального состояния мышц, которые обеспечивают динамическую активность нижних мочевых путей и дистальных отделов толстой кишки, мы использовали электромиографию (ЭМГ) мочевого пузыря и сфинктерного аппарата, анального сфинктера, мышц тазового дна. Для усиления биоэлектрической активности мышц нижних отделов мочевой системы и дистальных отделов толстой кишки использовали 
Огляди літератури, оригінальні дослідження, погляд на проблему

электромиограф 4-канальный фирмы «Медикор» (Венгрия). Данные ЭМГ оценивали по показателям среднего значения суммарной биоэлектрической активности.

Результаты. В статье представлены результаты лечения больных с сочетанной нейрогенной патологией нижних мочевых путей и дистального отдела толстой кишки. Оценка эффективности проводилась с помощью клинических и уродинамических обследований. Установлено, что электромиография, урофлоуметрия отображают функциональное состояние мочевыводящих путей и дистальных отделов толстой кишки при их сочетанной патологии. Полученные результаты были основой для обоснования принципов дифференцированного лечения больных с сочетанной нейрогенной патологией нижних мочевыводящих путей и дистальных отделов толстой кишки, что позволило повысить эффективность лечения. Консервативное лечение пациентов данной категории с помощью электростимуляции является эффективным.

Выводы. 1. Данные электромиографических и уродинамических исследований позволили разработать и оптимизировать методы лечения в зависимости от состояния тонуса нервно-мышечных структур нижних мочевых путей и дистальных отделов толстой кишки. 2. Комплексный дифференцированный подход к консервативному лечению направлен на коррекцию выявленных при электрофизиологическом и уродинамическом обследовании нарушений функционального состояния нижних мочевыводящих путей и дистальных отделов толстой кишки.

КЛЮЧЕВЫЕ СЛОВА: нейрогенные расстройства мочеиспускания; нейрогенная дисфункция кишечника; урофлоуметрия; электромиография; электростимуляция.

\section{TACTICS IN THE DIAGNOSIS AND TREATMENT OF PATIENTS WITH COMBINED NEUROGENIC PATHOLOGY OF THE LOWER URINARY TRACT AND DISTAL COLON

\author{
@S. O. Vozianov, M. P. Zakharash, P. V. Chabanov, Yu. M. Zakharash \\ N. A. Sevastyanova, V. Yu. Ugarov, A. S. Reprintseva \\ Institute of Urology, NAMS of Ukraine, Kyiv \\ O. Bohomolets National Medical University, Kyiv \\ Solomianskyi district Center of Primary Health Care No. 2, Kyiv
}

SUMMARY. Introduction. Neurogenic urination disorders combine a large group of urination disorders that occurs when the brain and spinal cord are damaged, leading pathways and centers of the bladder. This indicates the urgency of the problem and the need to develop diagnostic methods and their simultaneous treatment.

The aim of the study - to increase the effectiveness of treatment for women with a combined neurogenic pathology of the lower urinary tract and distal colon.

Materials and Methods. All patients with a combined neurogenic pathology of the lower sections of the urinary system and the lower sections of the colon had a comprehensive examination using both conventional and special diagnostic methods.

We used electromyography (EMG) of the bladder and sphincter apparatus, anal sphincter, pelvic floor muscles to study the functional state of the muscles that provide the dynamic activity of the lower urinary tract and distal colonies. To strengthen the bioelectric activity of the muscles of the lower sections of the urinary system and distal colons, 4-channel electromyograph, «Medikor» (Hungary), was used. The EMG data were evaluated for the mean values of total bioelectric activity.

Results and Discussion. The article presents the results of treatment of patients with combined neurogenic pathology of the lower urinary tract and the distal part of the large intestine. Efficacy was assessed using clinical and urodynamic surveys. It has been established that the electromyography of uroflowmetry reflects the functional state of the urinary tract and distal parts of the colon at their combined pathology. The obtained results were the basis for substantiating the principles of differentiated treatment of patients with combined neurogenic pathology of the lower urinary tract and distal colon, which allowed increasing the effectiveness of treatment. Conservative treatment of patients of this category by means of electrostimulation is effective.

Conclusions. 1. Data of electromyographic and urodynamic studies allowed to develop and optimize treatment methods depending on the state of tone of the neuromuscular structures of the lower urinary tract and distal colon. 2. The complex differential approach to conservative treatment is aimed at correction of the disorders of the functional state of the lower urinary tract and of the distal colon units revealed during the electrophysiological and urodynamic examination.

Key words: neurogenic disorders in urination; intestine neurogenic dysfunction; uroflowmetry; electromyography; electrostimulation.

Отримано 07.11.2017 